eISSN 2582 - 0559

“An Official Journal of IDA - Madras Branch”C2019.

Available online

\title{
CONSERVATIVE MANAGEMENT OF TOOTH SIZE ARCH LENGTH DISCREPANCIES-A REPORT OF TWO CASES
}

\author{
Dr. Shekar Shobana, Dr Krishnan Amudhalakshmi* \\ Department of Conservative Dentistry and Endodontics, \\ SRM Dental College and Hospital, Ramapuram, Chennai, Tamilnadu, India. \\ * Department of Dental Surgery, Government Vellore Medical College and Hospital, Tamilnadu, India.
}

To access \& cite this article Website: jidam.idamadras.com

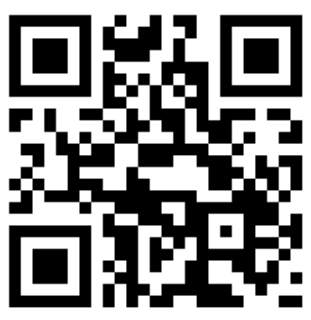

DOI:10.37841/jidam_2020_v7_i1_06

Address for correspondence:

Dr Shekar Shobana, MDS.,

No 4, 6th Avenue, Ramakrishna Nagar, Porur,

Chennai- 600116

E mail id: drshobana.bds@gmail.com

\section{ABSTRACT}

Tooth size arch length discrepancies ideally require orthodontic treatment. But in certain exceptional cases like spacing due to aggressive periodontitis, pathological migration and non-compliance of the patient to undergo comprehensive orthodontic procedure, the scenario demands deviation from the routine treatment approaches and to customise the treatment plan based on the patient's needs. This paper reports two cases: midline diastema in mandibular anteriors due to pathological migration managed with acrylic pontic retained by fiber reinforced composite restoration. The second case discusses anterior crowding managed conservatively by a fixed partial denture and the natural tooth pontic retained by fiber reinforced composite splint.

KEYWORDS: Aesthetic transformation, cosmetic recontouring, fiber reinforced composite, natural tooth pontic. 


\section{INTRODUCTION}

The face is the most important part of the body when determining physical attractiveness and the order of increasing importance is the nose, facial structure, eyes and the mouth respectively. ${ }^{1}$ Aesthetics being a subjective factor, is often necessary to formulate treatment plan according to the patient's requirement, within a short period of time. The condition might necessitate deviation from the established clinical protocols and achieve optimal aesthetics meanwhile adhering to the principles of minimal intervention.

Crowding and spacing of teeth are the two most commonly encountered malocclusion problems. These cases are usually treated by orthodontic correction. In exceptional cases, it may be necessary to manage the above mentioned conditions conservatively. This case report describes management of two common malocclusion(s) - crowding and spacing managed by conservative aesthetic approach. First case discusses lower anterior spacing due to pathological migration managed by acrylic tooth pontic retained by fiber reinforced composite. The second case describes the management of crowding in maxillary anteriors with mesiodens by extraction of malposed teeth and restoration with a fixed partial denture. Crowding of the mandibular anteriors was managed by extraction of malposed teeth which was retained as fiber reinforced natural tooth pontic. Cosmetic recontouring with direct composite restoration was done.

\section{CASE REPORT 1}

A 27 year old female patient reported to the Department of Conservative Dentistry and Endodontics, referred from the Department of Periodontics for aesthetic management of spacing in the lower anterior region due to pathological migration of teeth and for endodontic evaluation of 31 and 41 . The mandibular incisors were periodontally compromised and the patient was in the follow-up phase after periodontal therapy. The diastema in the lower anterior region was of aesthetic concern to the patient that raised the need for aesthetic intervention.

\section{Intra-oral Examination:}

Intra-oral examination revealed localized aggressive periodontitis involving 31, 41 with pathological migration [Fig.1(a)] which revealed a space of $3.5 \mathrm{~mm}$ between the mandibular central incisors as measured with digital calipers. The patient's periodontal condition precluded the use of 31,41 as abutments for fixed prosthesis whereas the spacing posed a potential threat to patient's aesthetics. As an interim management it was planned to close the space by using acrylic tooth pontic stabilized with fibre reinforced composite.

\section{Treatment plan:}

\section{First appointment:}

During the first visit, a study model was taken to assess the patient's overjet and overbite relation. The maxillary and mandibular anteriors were in normal overbite relation, whereas overjet was increased measuring about $4 \mathrm{~mm}$. Then the mesiodistal width of the mandibular centrals was measured accurately using calipers to assess the amount of tooth preparation required to accommodate the acrylic pontic. A suitable acrylic teeth was selected after shade matching.

Electric pulp testing for 41 exhibited normal response whereas 31 exhibited delayed response. On clinical examination 31 revealed grade II mobility and gingival recession. Intentional root canal treatment was planned for 31.

Digital Vernier calipers were used to measure the space and mesio distal dimension of 41 and 31 which was $5.5 \mathrm{~mm}$ and $5 \mathrm{~mm}$ respectively. This gave a total of $14 \mathrm{~mm}$ (mesio distal dimension of 31, 41 and diastema). It was thus decided to get an equal mesio distal dimension of $4.6 \mathrm{~mm}$ for 31,41 and the acrylic denture pontic. As 31 was to be endodontically treated, more reduction was planned in 31 $(1 \mathrm{~mm})$ and 41 was to be stripped ultra conservatively $(0.5 \mathrm{~mm})$ on the mesial aspect to create a total space of 4.6 $\mathrm{mm}$ for the acrylic denture pontic. Thus 31 and 41 in the dental stone models were stripped proximally and the selected acrylic denture pontic was also trimmed to check for fit.

\section{Second appointment:}

During the second visit, intentional single visit root canal treatment was done in 31 .

Third appointment:

During the subsequent visit 41,31 were stripped ultraconservatively on the proximal aspect to accommodate the acrylic pontic [Fig 1(b)]. Space of approximately $0.5 \mathrm{~mm}$ should exist between the pontic and the abutment teeth, which provides additional bulk of composite material and hence stronger connectors. ${ }^{2}$

Under rubber dam isolation using the split dam technique, Class III cavities were prepared in 31 and 41 [Fig.1(c)] from the lingual approach. The cavities were etched for 20 seconds using $37 \%$ orthophosphoric acid (NEtch, Ivoclar Vivadent, Leichenstein, Germany), rinsed for 20 seconds and air dried. Bonding agent (Tetric-N-Bond, Total Etch Dental Adhesive, Ivoclar Vivadent, Leichenstein, Germany) was applied and cured for 10 seconds. The acrylic tooth pontic was positioned and stabilized from labial aspect with flowable light cured composite resin (Te-Econom Flow, Ivoclar Vivadent, Leichenstein, Germany). The acrylic pontic was prepared as to maintain a modified ridge lap relation with the alveolar ridge. 
The desired length of the glass impregnated braided fiber reinforced composite (Interlig, Angelus, Londrina, PR Brazil) was measured and cut. The class III cavities in 31 and 41 were coated with flowable composite to ensure maximum wetting of the fiber and was stabilized in position using a Teflon coated composite instrument. The material was then light cured for 40 seconds [Fig.1(d)]. A second increment of flowable composite was added and again light cured for 40 seconds. Final finishing was done with Optra Pol (Ivoclar Vivadent, Leichenstein, Germany) [Fig1(e)]. The post-operative image shows the acrylic tooth pontic in place [Fig 1(f)].

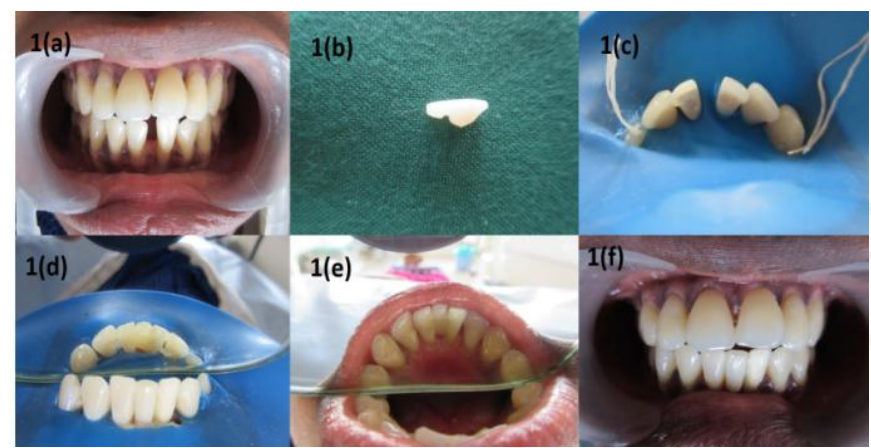

Fig 1(a): Pre-operative facial view showing midline spacing of the lower anteriors. Fig 1(b): Selection and preparation of the acrylic tooth as pontic. Fig 1(c): Preparation of Class III cavities in 31 and 41 for placement of the FRC composite . Fig 1(d): Acrylic tooth pontic try-in with FRC composite. Fig 1(e): Lingual view of the retained pontic. Fig 1(f): Labial view of the acrylic pontic

\section{CASE REPORT 2}

A 23-year old male patient reported with the chief complaint of crowded upper and lower front teeth and was referred from the Department of Orthodontics as the patient was not willing for comprehensive orthodontic treatment. The patient was seeking aesthetic rehabilitation, but the duration of treatment and financial constraints were exercising a great influence on the treatment plan.

Extra-oral examination revealed that the patients profile and divergence were within normal limits. No skeletal malocclusion was evident.

Intra-oral examination:

Intra-oral examination revealed the presence of severe crowding of maxillary anteriors. Patient gives recent history of extraction of 11 which was labially placed. 21 was disto labially rotated along its long axis and mesiodens was present. Mandibular anteriors were crowded with gingival recession in 31, 41 and Ellis class II fracture was present in 41 which was labially malposed [Fig 2(a) \& (b)]. Overjet and overbite were within acceptable ranges. The case was diagnosed as Angle's Class I molar relation with crowded maxillary and mandibular anteriors and the presence of maxillary mesiodens and missing 11, Ellis class II fracture in 41.

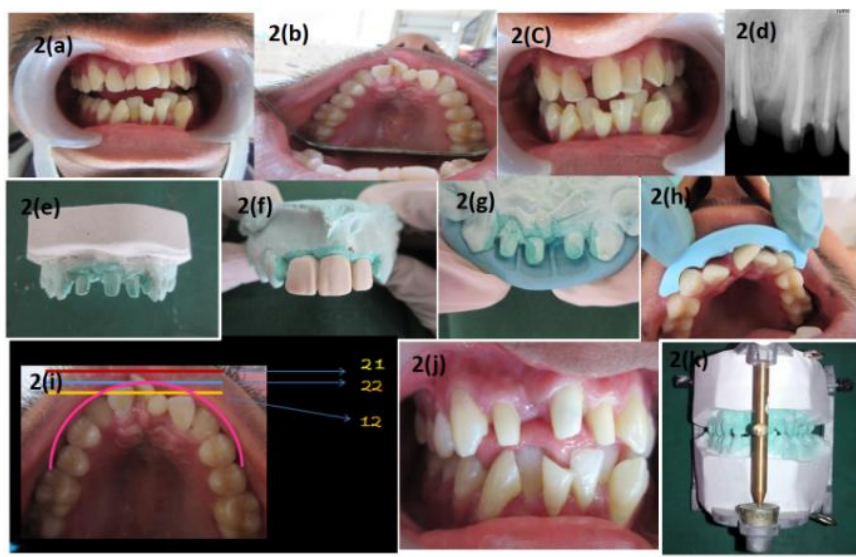

Fig 2(a): Pre-operative labial view. Fig 2(b): Pre-operative lingual view Fig 2(c): Labial view after extraction of mesiodens. Fig 2(d): Intentional RCT in 12, 21, 22. Fig 2(e): Mock tooth preparation on diagnostic cast. Fig 2(f): Mock wax up on prepared diagnostic cast. Fig 2(g): Silicone putty index prepared on the mock wax up. Fig 2(h): Silicone putty index used as a guide to tooth preparation. Fig 2(i): Lines depicting the position of the teeth lying within the arch form represented by a pink line; blue, yellow and red lines denote the relative labial positioning of 22,12 and 21 respectively relative to the arch form which will requires elective preparation to place the abutments within the desired arch form. Fig 2(j): Completed crown preparation in 12,11,21. Fig 2(k): Articulation of the secondary cast

\section{Treatment plan and procedure:}

The proposed treatment plan was as follows: For the maxillary arch: intentional root canal treatment in 12,21,22, extraction of mesiodens, fixed partial denture in 12,21,22. For the mandibular arch: extraction of 32 , the crown of which would be used as FRC retained natural tooth pontic, recontouring of 42, 43 and light cure composite restoration in 41. After thorough oral prophylaxis, extraction of mesiodens was done [Fig 2(c)] followed by intentional root canal treatment of 12,21,22 (Fig 2(d)]. This was followed by the extraction of the maxillary mesiodens. Using the diagnostic casts as guidance, mock tooth preparation was done on the study model [Fig 2(e)] and a mock-up wax pattern was made with the mockup wax [Fig 2(f)]. A silicone putty index was made over the mockup to guide the tooth preparation [Fig 2(g)] and also to determine the facial and incisal position of the final restoration. The putty index was placed periodically over the abutment teeth during preparation to assess the amount of clearance obtained and also to conserve tooth structure that was lingually inclined [Fig 2(h)]. Figure 2(i) is a depiction of the analysis of the relative labio-lingual positioning of teeth. Fig 2(j) shows the completed tooth preparation done with the putty index as the guide. Impressions were recorded with elastomeric impression materials and the secondary casts were articulated [Fig $2(\mathrm{k})$ ]. Porcelain fused to metal crowns were fabricated and cementation was done with Fuji Type I glass 
ionomer luting cement (GC, Tokyo, Japan). 13 was recontoured and restored with light cure composite restoration to mimic 12 (TetricN-Ceram, Ivoclar Vivadent, Leichenstein, Germany).

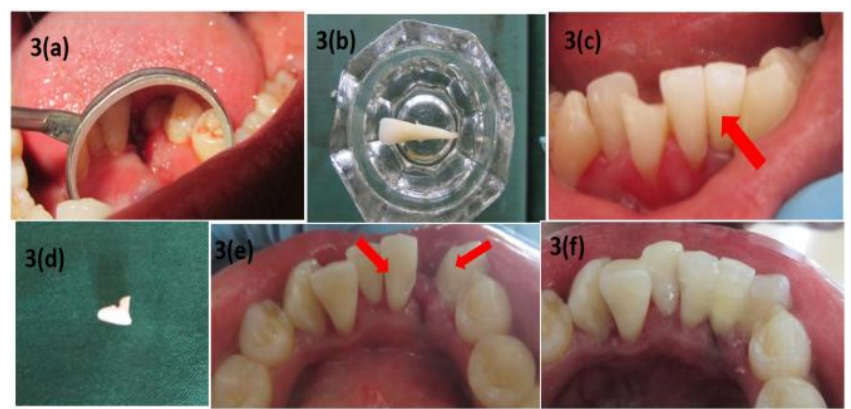

Fig 3(a): Extraction of the lingually aligned 32. Fig 3(b): Extracted tooth stored in sterile saline. Fig 3(c): Natural tooth pontic prepared proximally to fit in the space between 31 and 33. Fig 3(d): Decoronation and lingual slot preparation of natural tooth pontic 32. Fig 3(e): Class III cavity preparation in 31 and 33. Fig 3(f): Fiber reinforced composite retained natural tooth ponic in 32 .

Under local anaesthesia with 1:100000 Adrenaline (Lignox, Warren pharmaceuticals), extraction of 32 was done [Fig 3(a)] and stored in sterile saline [Fig 3(b)]. The extracted tooth was decoronated and the pulp chamber was debrided. The prepared tooth was stored in sterile saline until further use. After one week, the stored tooth crown was proximally sliced to fit into the extraction space [Fig 3(c)] and the pulp chamber was sealed with Glass Ionomer Cement (Fuji II, GC Tokyo, Japan). A horizontal slot measuring $2 \mathrm{~mm}$ was placed on the lingual aspect of 32 [Fig 3(d)]. Under rubber dam isolation, class III cavities were prepared on the mesial and distal aspect of 31 and 33 respectively [Fig 3(e)] and FRC retained natural tooth pontic was done as previously discussed. [Fig 3(f)]. The preoperative and post-operative comparative images are seen in Figures 4 (a), (b) and (c) respectively.

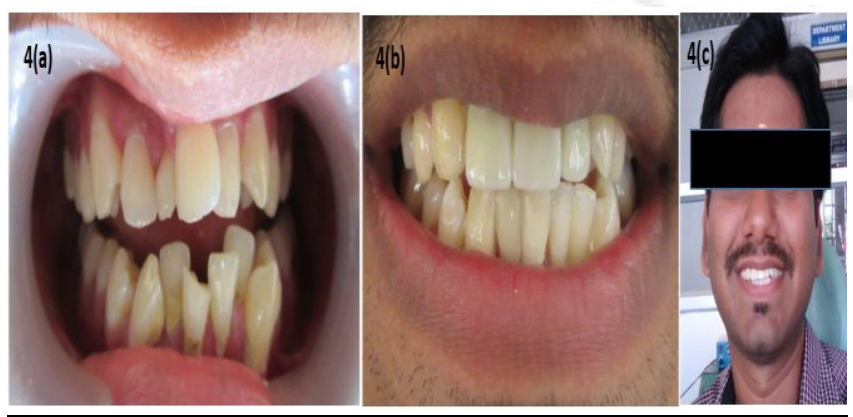

Fig 4(a): Pre-operative labial view. Fig 4(b): Post-operative labial view. Fig 4(c): Post-operative profile view

\section{DISCUSSION}

Even though multidisciplinary treatment is the key to establish an ideal and a perfect smile component, ${ }^{3,4}$ the need to attend to the patient's aesthetics within a short duration makes alternative options like recontouring and direct restorations feasible. ${ }^{5,6}$ The patient's choice of treatment is a vital element for the success of any procedure as it involves the psychological, physical and financial dimension of the individual. ${ }^{7}$

Case 1: In the first case, there was localized aggressive periodontitis of the lower anteriors and the patient was in the follow-up phase of treatment. An interim aesthetic procedure was needed before a definitive treatment could be instituted.

Case 2: In the second case, owing to patient's aesthetic needs and non-compliance towards orthodontic treatment a conservative management was planned. Mesiodens was extracted and fixed partial denture was planned using 12, 21 and 22 as abutments to replace 11, 21, 22. Aesthetic pre-evaluative temporary technique (APT) is usually used to guide tooth preparation for veneers. ${ }^{8}$ In this case, the silicon putty index served as a guide to tooth preparation and to gauge preparation depth as the abutments required unequal tooth preparations due to severe rotation. Cosmetic recontouring or aesthetic transformation is a well documented procedure in the literature. ${ }^{3,9,10,11}$ In this case, 13 was recontoured to mimic 12 by additive technique with direct composite. This technique is both biologically and economically affordable and requires less appointments. ${ }^{10}$

In both the cases, it was not possible to establish perfect midline symmetry. Pinho et $\mathrm{al}^{12}$ has stated that midline shift became perceptible when equal to or greater than $1 \mathrm{~mm}$ for Orthodontists and $3 \mathrm{~mm}$ for Prosthodontists and lay persons could make no detections in midline deviation. Further Ker et $\mathrm{al}^{13}$ has concluded from his study that "ranges of acceptable deviation variations for smile characteristics are large, and practitioners should avoid unnecessarily sensitizing patients to minor discrepancies".

Fiber reinforced composites (FRC) are used as long term restorations as they overcome the drawbacks of conventional composites like low fracture resistance and resilience. Many investigators have confirmed the reinforcing effect of FRCs on different polymer types ${ }^{14,15}$ This reinforcing effect can be attributed to the transfer of stresses from the weak polymer matrix to the fibers with high tensile strength. ${ }^{16}$ In the present case, Interlig (Angelus) was used, which is an impregnated, braided, glass fiber reinforced composite with the ability to dissipate forces in all directions. Glass fibers are treated with silane chemical coupling agent to allow dental resins to chemically adhere to the glass fiber strands. ${ }^{17}$ Kolbeck et al reported that glass fibers performed better than polyethylene fibers due to preimpregnation with light cured composite which ensures a good bond with the composite resin making Intelig (Angelus) the ideal material of choice in this case. ${ }^{18}$

In case 1 , there was spacing due to pathological migration related to localized aggressive periodontitis of the mandibular anteriors, not associated with tooth loss. A definitive management in this case would be an implant or 
fixed partial denture. But due to the poor prognosis of the abutment teeth $(31,41)$, placement of a fixed prosthesis or implant was contraindicated in that region because of the existing pathological destructive process in the bone. So this case became an ideal candidate for acrylic pontic and FRC resin. A chairside FRC prosthesis offers a fast, minimally invasive approach for tooth replacement that combines all of the benefits of the FRC material for aesthetic, functional and potentially durable result. An acrylic tooth or a natural tooth (in the case of extraction of a periodontally-involved incisor) can be used as a pontic.

FRC has an acceptable strength because of good integration of fibers with the composite resin, leading to clinical longevity and can be completed in a single appointment. In addition, the appliance can easily be repaired in case of fracture due to wear and tear. Moreover, it meets patients' aesthetic expectations. ${ }^{19}$

\section{CONCLUSION}

Aesthetic dentistry is purely elective. The need of the patients dictates the choice of treatment and is based on discretionary income. The success of cosmetic dentistry depends on motivation and aesthetic choices happen to be emotional. It would be prudent to conclude that the skill of clinical decision making coupled with application of principles of aesthetics helps to achieve predictable clinical outcomes and aids in establishing aesthetics within a short span of time.

\section{FINANCIAL SUPPORT AND} SPONSORSHIP:

Nil

\section{CONFLICTS OF INTEREST:}

There are no conflicts of interest.

\section{REFERENCES}

1. Patzer GL. The Physical Attractiveness Phenomena. New York: Plenum Press, 1985;69-70.

2. Mishra N, Jurel SK, Singh RD. Glass fiber reinforced bridge using acrylic denture tooth pontic- A multidisciplinary approach. Int $\mathbf{J}$ Pros Dent 2013:4(2):56-59.

3. Claman L, Alfaro MA, Mercado A. An interdisciplinary approach for improved esthetic results in the anterior maxilla. $\mathrm{J}$ Pros Dent 2003;89(1):1-5.

4. Calamia JR, Levine JB, Lipp M, Cisneros G, Wolff MS. Smile design and treatment planning with the help of a comprehensive esthetic evaluation form. Dent Clin North Am 2011; 55(2): 187-209.

5. Dietschi D. Optimizing smile composition and esthetics with resin composites and other conservative esthetic procedures. Eur J Esthet Dent 2008;3(1):14-29.

6. Mathias P, Freitas da Silva EV, Aguiar TR ,Andrade AS, Azevedo J.A Conservative esthetic approach using enamel recontouring and composite resin restorations. Case Rep Dent 2016; 2016: 1-5.

7. Chu $\mathrm{CH}$, Zhang $\mathrm{CF}$, Jin LJ. Treating a maxillary midline diastema in adult patients - a general dentist's perspective. J Am Dental Ass 2011; 142(11): 1258-1264.

8. Gurel G, Morimoto S, Calamita MA, Coachman C, Sesma N. Clinical Performance of Porcelain Laminate Veneers: Outcomes of the Aesthetic Preevaluative Temporary (APT) Technique. Int $\mathbf{J}$ Periodontics Restorative Dent 2012;32:625-635.

9. Geoffrion J. Transformation of a lateral incisor to a central incisor with a ceramometal crown. Rev Odontostomatol 1989 Sep-Oct;18(5):385-93.

10. Pontons-Melo JC, Atzeri G, Collares FM, Hirata R. Cosmetic recontouring for achieving anterior esthetics. Int J Esthet Dent 2019;14(2):134-146.

11. Epstein MB, Mantzikos T, Shamus IL . Esthetic recontouring. A team approach. N Y State Dent J 1997;63(10):35-40.

12. Pinho s, Ciriaco C, Faber J, Lenza MA . Impact of dental asymmetries on the perception of smile esthetics - Am J Orthod Dentofacial Orthop. 2007;32(6): 748-53.

13. Ker AJ, Chan R, Fields HW, Beck M, Rosenstiel S. Esthetics and smile characteristics from the layperson's perspective : a computer based surveyJ Am Dent Assoc 2008 Oct; 139(10):1318-27.

14. Kolbeck C, Rosentritt M, Behr M, Lang $\mathrm{R}$, Handel G. In-vitro study of fracture strength and marginal adaptation of polyethylene-fiber reinforced- composite versus glass-fiber-reinforcedcomposite fixed partial dentures. J Oral Rehabil 2002;29:668-74.

15. Aydin C, Yilmaz A, Caglar A. Effect of glass reinforcement on the flexural strength of denture base resin. Quintessence Int 2002;33:457-63.

16. Nohrstrom TJ, Valittu PK, Yli-Urpo A. The effect of placement and quantity of glass fibers on the fracture resistance of interim fixed partial dentures. Int J Prosthodont 2000;13:72-8. 
17. Strassler HE, Tomona N \& Spitzangel JK. Stabilizing periodontally compromised teeth with fiber-reinforced composite resin. Dent Today 2003; 22(9):102-104.

18. Kolbeck C, Rosentritt M, Lang R, Handel G. Invitro study of fracture strength and marginal adaptation of polyethylene-fiber-reinforced composite versus glass-fiber-reinforced-composite fixed partial dentures. J Oral Rehabil 2002;29:66874.

19. Karman AI, Kir N, Belli S. Four applications of reinforced polyethylene fiber material in orthodontic practice. Am J Orthod Dentofac Orthop 2002;121:650-4. 